\section{A) Check for updates}

Cite this: Food Funct., 2019, 10 6624

Received 16th July 2019

Accepted 30th August 2019

DOI: $10.1039 /$ c9fo01554j

rsc.li/food-function

\title{
Acrylamide in biscuits commercialised in Spain: a view of the Spanish market from 2007 to 2019
}

\begin{abstract}
Marta Mesías, (D) * Francisco J. Morales (D) and Cristina Delgado-Andrade (D)
The biscuit industry has evolved in the last decades with the inclusion of alternative cereals, pseudocereals and other ingredients in traditional recipes, which allows current consumers' needs to be met. The dough composition, thermal treatment applied during baking, low moisture, and high rate of consumption make biscuits important contributors to daily exposure to acrylamide in Western diets. Acrylamide was determined by LC-ESI-MS/MS in 80 commercial biscuits marketed in Spain. The mean acrylamide content was $343 \mathrm{\mu g} \mathrm{kg}^{-1}$ (from <20 to $2144 \mathrm{\mu g} \mathrm{kg}^{-1}$ ). Rye, teff and oat-based biscuits exhibited the highest content $\left(2144,1559\right.$ and $1424 \mathrm{\mu g} \mathrm{kg}^{-1}$, respectively). $70 \%$ of the samples were below the benchmark level established by the EU Regulation 2017/2158. Compared to our previous prospective study in 2007 on the Spanish market, acrylamide has experienced an important decline (45\%) in wheatbased formulations, demonstrating the effectiveness of the mitigation strategies applied in the sector. However, when all samples were considered, a slight non-significant decrease (18\%) was observed. This fact suggests that the reformulation of traditional recipes with innovative cereals and ingredients could increase the acrylamide content in biscuits despite the mitigation strategies applied. Therefore, forthcoming reviews of the regulation should consider establishing categories in biscuits according to the main cereal, as has already been established in breakfast cereals.
\end{abstract}

\section{Introduction}

Biscuits are a cereal-based foodstuff whose traditional recipe also includes sugars and fats that are mixed and subsequently baked at high temperature for short times (up to $200{ }^{\circ} \mathrm{C}$ for less than $20 \mathrm{~min})$ in order to reduce the water content $(<10 \%)$ and to promote an appetizing golden-brown surface. ${ }^{1}$ To meet new consumers' demands for health and well-being criteria, biscuit producers are constantly seeking new ideas and formulations that promote the interest of the population. For this reason, more recently traditional cereals have been mixed with or replaced by other cereals, pseudo-cereals and ingredients that allow the launching of new products to such a competitive market. Those new formulations are in some cases gluten-free alternatives intended for people with celiac disease or contain innovative ingredients such as spelt, kamut, teff and/or different seeds, in order to cover different lifestyles. ${ }^{2}$

Baking is a complex process inducing physical, chemical and biochemical changes in the cereal matrix, such as volume expansion, evaporation of water and formation of a porous structure, denaturation of proteins, starch gelatinization, crust

Institute of Food Science, Technology and Nutrition, ICTAN-CSIC, José Antonio Novais 10, 28040 Madrid, Spain.E-mail: mmesias@ictan.csic.es; Tel: +34915492300 formation and development of a desirable taste and pleasant flavours and browning. ${ }^{3}$ One of the main chemical reactions involved in the generation of those colours and flavours is the Maillard reaction, which is essential for the production of acrylamide. ${ }^{4}$ Since this compound was identified by the European Food Safety Authority (EFSA) as a public health concern due to its relation with the development of different types of cancer, ${ }^{5}$ important efforts have been made to monitor acrylamide levels in processed products during the past few years, making companies aware of this problem and the need of mitigation strategies to reduce acrylamide generation. After previous recommendations, ${ }^{6,7}$ the European Commission has established new benchmark levels for the main food sources of acrylamide and set mitigation measures. ${ }^{8}$

Cereal products are one of the main contributors to acrylamide exposure and therefore are included among the foodstuffs regulated by the European Commission. ${ }^{5}$ The indicative values set by the European Commission for acrylamide in biscuits have been reduced from $500^{7}$ to a benchmark value of $350 \mu \mathrm{g} \mathrm{kg}{ }^{-1}{ }^{8}$ The food industry launched the acrylamide toolbox that compiles strategies to mitigate the formation of this contaminant in a number of food commodities. ${ }^{9}$ The acrylamide toolbox recommends (i) the use of cereal varieties with low asparagine content, (ii) controlling the use of potential acrylamide-forming ingredients (raising agents, nuts, ovendried fruit, bran sources, etc.) and (iii) the optimization of the 
product size as well as the adjustment of the thermal input. Additionally, biscuit manufacturers aimed to consider the use of asparaginase. This is proven to be one of the most efficient tools to reduce acrylamide levels in this food category and if applied at a low level, no negative effects on the organoleptic profile of the final product have been described. ${ }^{9}$

In 2007, our research team performed a prospective study on acrylamide content in biscuits marketed in Spain to estimate their contribution to the acrylamide exposure of the population. The study pointed out an average value of $423 \mu \mathrm{g}$ $\mathrm{kg}^{-1}$ and a median of $268 \mu \mathrm{g} \mathrm{kg}{ }^{-1} .{ }^{10}$ In the framework of the new regulation and applying all the mitigation strategies proposed in the past few years, a reassessment of acrylamide occurrence in Spanish marketed biscuits is needed. Moreover, this study will allow updating the risks associated with the evolution of the biscuit market towards formulations with health claims and special needs.

This work aimed to obtain a reliable evaluation of the acrylamide content in the Spanish biscuit market after the EU Regulation for acrylamide and secondly to update the contribution of this food group to the dietary acrylamide exposure of the population. The results are compared with data previously reported by our research group in 2007 , in order to discuss the evolution of this food sector over the last decade as well as the effectiveness of the mitigation strategies implemented by the cereal industry.

\section{Materials and methods}

\subsection{Reagents and chemicals}

Potassium hexacyanoferrate(II) trihydrate (98\%, Carrez-I) and zinc acetate dihydrate ( $>99 \%$, Carrez-II) were obtained from Sigma (St Louis, USA). ${ }^{13} \mathrm{C}_{3}$-labelled acrylamide (99\% isotopic purity) was obtained from Cambridge Isotope Laboratories (Andover, MA, USA). Formic acid (98\%) was obtained from Panreac (Barcelona, Spain). Deionized water was obtained from a Milli-Q Integral 5 water purification system (Millipore, Billerica, MA, USA). Reversed-phase Oasis-HLB cartridges (30 mg, $1 \mathrm{~mL}$ ) were obtained from Waters (Milford, MA, USA).
Syringe filter units $(0.45 \mu \mathrm{m}$, cellulose $)$ were purchased from Análisis Vínicos (Tomelloso, Ciudad Real, Spain). All other chemicals, solvents and reagents were of analytical grade.

\subsection{Samples}

Eighty commercial biscuits from 30 different producers were purchased from different supermarkets in January-February 2019. Samples include hard sweet biscuits (Marie type, 'Dorada', breakfast, etc.), short dough biscuits (caramelised, digestives, printed, moulded, etc.), and cookies (ginger crunch, wire-cut, egg, oat, Danish butter, etc.). Biscuits containing dried fruits, nuts, chocolate or jam as well as those intended for the infant population were excluded from this study to avoid bias during data interpretation. Average nutritional composition was calculated based on the information declared in the package (Table 1). Samples were classified according to several variables: cereal (predominant cereal/mixture of them), type of grain (refined/wholegrain), protein content (below or above $7.5 \% \mathrm{w} / \mathrm{w}$ ), fibre content (below or above $5 \% \mathrm{w} / \mathrm{w}$ ), sugar content (below or above $20 \% \mathrm{w} / \mathrm{w}$ ), gluten free (yes/no), presence of butter, egg, ammonium carbonate or sodium carbonate in the recipe (yes/no) and target consumption (normal/dietetic). Samples were mixed and thinly ground to assure a homogeneous mixture, placed in a polyethylene container, sealed under vacuum and stored at $4{ }^{\circ} \mathrm{C}$ until analysis.

\subsection{LC-ESI-MS-MS determination of acrylamide}

Sample extraction and cleaning were based on a method described by Mesías and Morales ${ }^{11}$ and ISO:EN:16618:2015 with minor modifications. The ground sample was weighed and mixed with water in polypropylene centrifugal tubes. The mixture was spiked with $\left[{ }^{13} \mathrm{C}_{3}\right]$-acrylamide methanolic solution as the internal standard and later homogenised (Ultra Turrax, IKA, Mod-T10 basic, Germany) for $10 \mathrm{~min}$. Afterwards, the sample was treated with Carrez I (15 g potassium ferrocyanide/ $100 \mathrm{~mL}$ water) and Carrez II (30 g zinc acetate/100 mL water) solutions and centrifuged ( $9000 \mathrm{~g}$ for $10 \mathrm{~min}$ ) at $4{ }^{\circ} \mathrm{C}$. The samples were cleaned by using Oasis-HLB cartridges and filtered through a $0.45 \mu \mathrm{m}$ filter into an amberlite LC-MS vial.

Table 1 Average nutritional composition of the whole dataset of biscuits as provided by the manufacturer and grouped according to the predominant cereal. Data are expressed per $100 \mathrm{~g}$ of sample

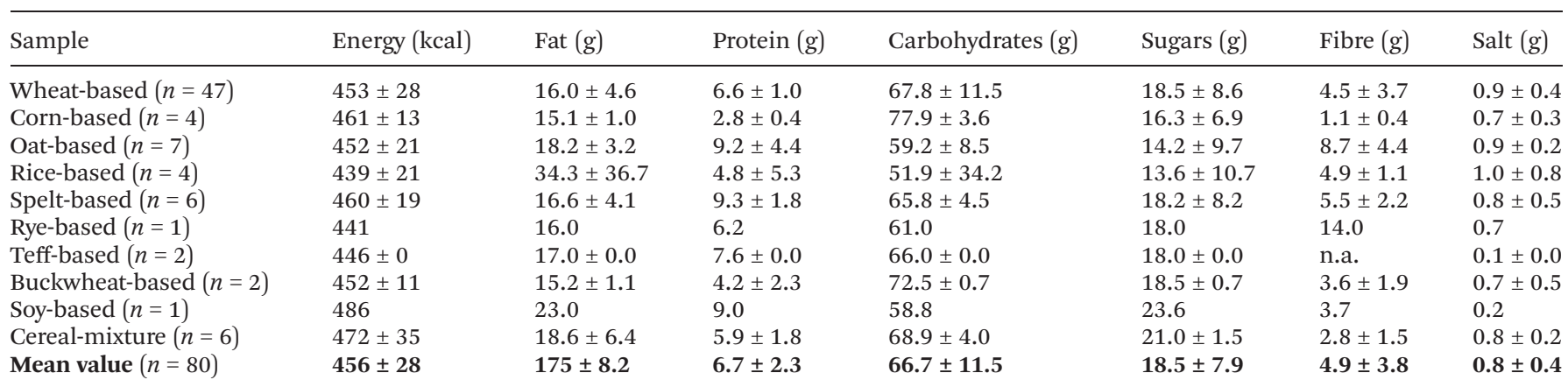

Values are mean \pm SD. n.a. indicates not available data. 
Sample extracts and calibration standards were analysed by LC-ESI-MS-MS, as described by Mesias and Morales. ${ }^{11}$ The accuracy of the results was demonstrated with the participation in different proficiency tests launched by the Food Analysis Performance Assessment Scheme (FAPAS) program. Samples of biscuits, crispbread, potato crisps and French fries were analyzing leading to $z$-scores of -0.2 (Test 3044, Jan 2014), 0.3 (Test 3056, May-July 2015), 0.2 (Test 3065, May-June 2016), -0.2 (Test 3071, Feb-March 2017), -0.3 (Test 3080, FebMarch 2018), 0.0 (Test 3085, Sep-Oct 2018) and 0.3 (Test 3089, Feb-2019). Precision (reproducibility) was lower than $10 \%$ and recovery was between 84 and 109\%. The limit of quantitation was set at $20 \mu \mathrm{g} \mathrm{kg}{ }^{-1}$. Analyses were performed in duplicate and the results were expressed as $\mu \mathrm{g} \mathrm{kg}{ }^{-1}$ of product.

\subsection{Food consumption data}

Dietary exposure to acrylamide from the whole biscuit category as well as biscuits grouped according to the different type of cereals was estimated combining the data of total per capita consumption of biscuits (5.24 kg per person per year) established by the Spanish Ministry of Agriculture, Food and Environment ${ }^{12}$ and the acrylamide content in samples.

\subsection{Statistical analysis}

Statistical analyses were performed using SPSS version 23 (SPSS, Chicago, IL). Data were expressed as mean \pm standard deviation (SD). Student's $t$-test was used to identify the overall significance of differences. All statistical parameters were evaluated at $p<0.05$ significance level.

\section{Results and discussion}

\subsection{Nutritional composition of biscuits}

Table 1 depicts the overall nutritional composition of biscuits as declared by the manufacturer and grouped according to the main cereal in the formulation. The labelling provides valuable information of the ingredients and their composition to better characterise the biscuit and secondly the relationship with the acrylamide content. However, there is a limitation since the information related to the type of processing and the technology applied is missing. 19 biscuits were formulated only by wheat $(n=17)$ and rice $(n=2)$, whereas most of the samples were multi-cereal biscuits, based mainly on wheat $(n=47)$, corn $(n=4)$, oat $(n=7)$, rice $(n=4)$, spelt $(n=6)$, and a mixture of cereals $(n=6)$. Biscuits containing rye, teff, buckwheat or soy were represented by 1 or 2 samples. This fact depicts the product variability which is the current situation of the Spanish biscuit market and probably also in other European countries. All biscuits showed close mean values for energy (439-486 kcal per $100 \mathrm{~g}$ ) whereas higher differences were observed in other nutritional parameters. Fat content ranged between $15.1 \mathrm{~g}$ per $100 \mathrm{~g}$ for corn-based biscuits and $34.3 \mathrm{~g}$ per $100 \mathrm{~g}$ for rice-based biscuits. In contrast, the corn group presented the highest ( $77.9 \mathrm{~g}$ per $100 \mathrm{~g}$ ) and the rice group the lowest (51.9 g per $100 \mathrm{~g}$ ) content of carbohydrates. The overall protein content was below $10 \%$, and the lowest and highest protein contents were for the formulations based on corn (2.8\%) and oat (9.2\%). Minimum and maximum fibre contents were described for corn ( $1.1 \mathrm{~g}$ per $100 \mathrm{~g}$ ) and rye-based biscuits (14.0 g per $100 \mathrm{~g}$ ). Sugars ranged between 13.6 and $23.6 \mathrm{~g}$ per $100 \mathrm{~g}$, for rice and soy, respectively, whereas salt content ranged between 0.1 and $1.0 \mathrm{~g}$ per $100 \mathrm{~g}$ in teff and rice biscuits, in each case. Biscuits were grouped according to the predominant cereal, type of grain (refined and wholegrain), protein content (above or below 7.5\%), fibre content (above or below 5\%), sugar content (above or below 20\%) and the presence/absence of butter, egg and baking aids in the formulation. Additionally, classification as gluten free samples and dietetic biscuits (with low content of fat and/or sugar) was also considered as interesting factors to establish comparisons in the dataset (Table 2).

\subsection{Acrylamide levels in biscuits: the effect of type of cereal and other factors on its formation}

Eighty commercial biscuits from 30 different producers were analysed for the acrylamide content. Acrylamide ranged from lower than $20 \mu \mathrm{g} \mathrm{kg}^{-1}$ (LOQ) to $2144 \mu \mathrm{g} \mathrm{kg} \mathrm{kg}^{-1}$ (Fig. 1), with an average value of $347 \mu \mathrm{g} \mathrm{kg} \mathrm{k}^{-1}$ and a median value of $234 \mu \mathrm{g} \mathrm{kg}^{-1}$. These values are higher than those reported by the EFSA ${ }^{5}$ for the category of 'biscuits and wafers' from different

Table 2 Average acrylamide content in biscuit samples grouped according to different factors

\begin{tabular}{|c|c|c|}
\hline Factor & $n$ & Acrylamide \\
\hline \multicolumn{3}{|l|}{ Type of grain } \\
\hline Refined & 50 & $287 \pm 388 \mathrm{a}$ \\
\hline Wholegrain & 30 & $448 \pm 376 \mathrm{a}$ \\
\hline \multicolumn{3}{|c|}{ Protein content } \\
\hline$<7.5 \%$ & 56 & $300 \pm 366 \mathrm{a}$ \\
\hline$>7.5 \%$ & 24 & $458 \pm 389 \mathrm{a}$ \\
\hline \multicolumn{3}{|l|}{ Fibre content } \\
\hline$<5 \%$ & 56 & $282 \pm 308 \mathrm{a}$ \\
\hline$>5 \%$ & 24 & $403 \pm 457 \mathrm{a}$ \\
\hline \multicolumn{3}{|l|}{ Sugar content } \\
\hline$<20 \%$ & 39 & $455 \pm 483 \mathrm{~b}$ \\
\hline$>20 \%$ & 41 & $245 \pm 235 \mathrm{a}$ \\
\hline \multicolumn{3}{|c|}{ Presence of butter } \\
\hline No & 74 & $369 \pm 396 a$ \\
\hline Yes & 6 & $81 \pm 29 \mathrm{a}$ \\
\hline \multicolumn{3}{|c|}{ Presence of egg } \\
\hline No & 67 & $386 \pm 413 \mathrm{~b}$ \\
\hline Yes & 13 & $150 \pm 85 a$ \\
\hline \multicolumn{3}{|l|}{ Gluten free } \\
\hline No & 66 & $339 \pm 365 \mathrm{a}$ \\
\hline Yes & 14 & $387 \pm 500 \mathrm{a}$ \\
\hline \multicolumn{3}{|c|}{ Presence of sodium carbonate } \\
\hline No & 5 & $66 \pm 29 a$ \\
\hline Yes & 75 & $366 \pm 394 a$ \\
\hline \multicolumn{3}{|c|}{ Presence of ammonium carbonate } \\
\hline No & 7 & $176 \pm 335 \mathrm{a}$ \\
\hline Yes & 73 & $364 \pm 392 \mathrm{a}$ \\
\hline \multicolumn{3}{|c|}{ Dietetic biscuit } \\
\hline No & 68 & $369 \pm 415 \mathrm{a}$ \\
\hline Yes & 12 & $221 \pm 119 a$ \\
\hline
\end{tabular}

Data are mean \pm SD $\left(\mu \mathrm{g} \mathrm{kg}{ }^{-1}\right)$. Different letters within the same factor indicate statistical differences $(p<0.05)$. 


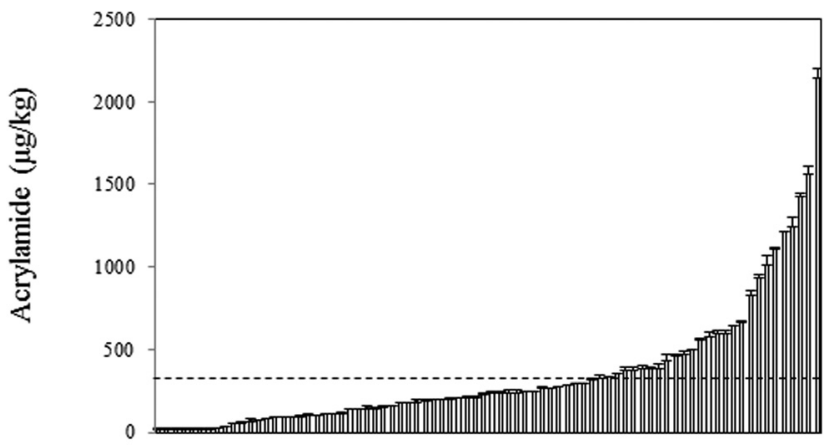

Biscuits

Fig. 1 Bar graph of acrylamide content in biscuits. The dotted line indicates the benchmark level $\left(350 \mu \mathrm{g} \mathrm{kg}^{-1}\right)$ established by the European Commission. $^{8}$

European countries (mean value: $201 \mu \mathrm{g} \mathrm{kg}^{-1}$; median value: $103 \mu \mathrm{g} \mathrm{kg}{ }^{-1}, n=682$ ). Seven samples showed acrylamide levels below the LOQ.

Our data are close to the mean and median values measured in a Swedish study of dietary intake of acrylamide for the category cookies/biscuits/wafers (300 and $230 \mu \mathrm{g} \mathrm{kg}^{-1}$, respectively, $n=11)^{13}$ and to the prospective sampling carried out in Italian biscuits (298 and $200 \mu \mathrm{g} \mathrm{kg}{ }^{-1}$, respectively, $n=$ 44). ${ }^{14}$ They are also in the same order of magnitude as those reported by Matthys et al. ${ }^{15}$ for conventional Belgium biscuits (range $20-1514 \mu \mathrm{g} \mathrm{kg}^{-1}, n=6$ ) and, more recently, by Alyousef et $a .^{16}$ for Syrian corn and wheat-based biscuits (range 57-1433 $\left.\mu \mathrm{g} \mathrm{kg} \mathrm{kg}^{-1}, n=87\right)$. However, they are lower than the mean value of $495 \mu \mathrm{g} \mathrm{kg}{ }^{-1}(n=27)$ determined by Cengiz and Gündüz ${ }^{17}$ during the evaluation of acrylamide exposure among Turkish toddlers from selected cereal-based products.

The European Regulation ${ }^{8}$ set $350 \mu \mathrm{g} \mathrm{kg}^{-1}$ as the benchmark level of acrylamide in biscuits and wafers. Compared to this value, $30 \%$ of the samples $(n=24)$ in this survey exceeded the reference level. Contrary to the food group of breakfast cereals, the Regulation does not establish categories depending on the type of cereal used in the formulation. In order to understand the contribution of different cereals to the acrylamide content in biscuits, samples were grouped according to the main cereal in the recipe (Fig. 2). The highest acrylamide contents were observed in rye-based samples $\left(2144 \mu \mathrm{g} \mathrm{kg}^{-1}\right)$ followed by those formulated with teff $\left(1559 \mu \mathrm{g} \mathrm{kg}^{-1}\right)$ and oat $\left(1424 \mu \mathrm{g} \mathrm{kg}^{-1}\right)$. In contrast, rice, corn and wheat-based biscuits displayed the lowest levels. These results may be explained by the presence of acrylamide precursors in these cereals, which together with other ingredients in the recipe and the extent of the processing conditions applied contribute to the generation of process contaminants. ${ }^{18,19}$

Asparagine and reducing sugars are the main precursors for acrylamide formation in food matrices and in cerealderived products the critical factor is the free asparagine content. ${ }^{20}$ The protein content and amino acid composition differ within cereal varieties and, therefore, in the absence of

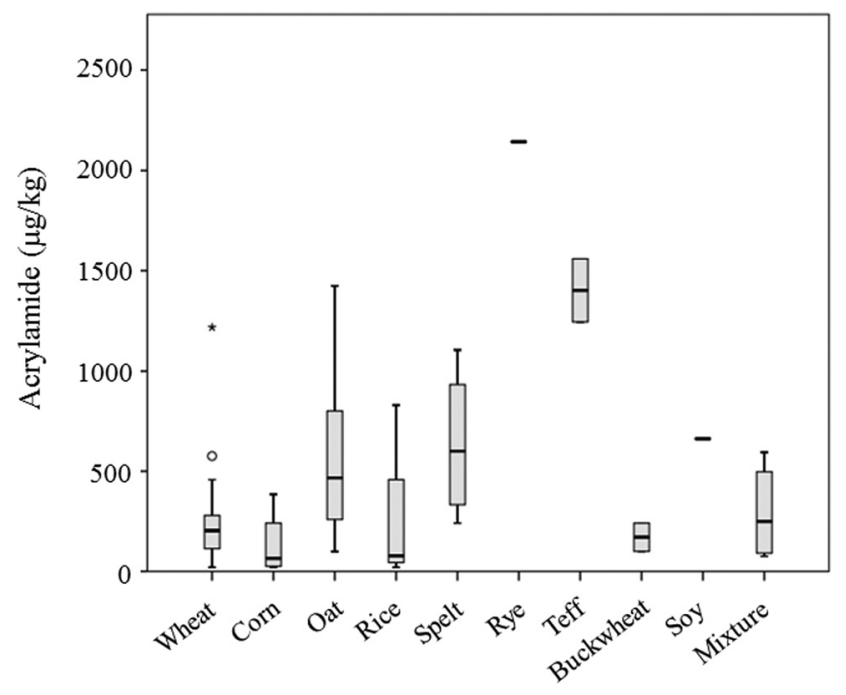

Fig. 2 Acrylamide content in biscuits grouped according to the predominant cereal.

other ingredients, the type of cereal used in the formulation of biscuits will influence drastically the acrylamide formation. ${ }^{9}$ Przygodzka et $a .^{21}$ reported that rye flour contained high levels of asparagine (322 $\mathrm{mg} \mathrm{kg}^{-1}$ ) as compared with wheat (78 $\mathrm{mg} \mathrm{kg}^{-1}$ ) and spelt (173 $\mathrm{mg} \mathrm{kg}^{-1}$ ) flours, promoting greater levels of acrylamide in rye bread, intermediate levels in spelt bread and lower levels in wheat bread. These results are in agreement with those observed in the present study. A similar trend for free asparagine was described by Claus et al. ${ }^{22}$ for wheat flour (1.74-19.05 $\mathrm{mg}$ per $100 \mathrm{~g})$, spelt flour (6.46-12.17 mg per $100 \mathrm{~g}$ ) and rye flour (41.37-44.10 mg per $100 \mathrm{~g})$. As reported by Žilić et al., ${ }^{23}$ rye followed by oat present the highest content of free asparagine and, therefore, they have an important potential for acrylamide formation. Teff has been described to contain a high percentage of protein (10.2-11.6\%), within which the contribution of aspartic acid/ asparagine ranges between 3.2 and $7.9 \%$, depending on the protein fraction considered (albumins + globulins, prolamins or glutelins). ${ }^{24}$ Therefore, the high concentration of acrylamide detected in biscuits based on rye, teff and oat flours could be justified by the high content of free asparagine in these cereals. On the other hand, it is known that corn and rice are grains with a low presence of asparagine, ${ }^{8}$ a fact supporting the low acrylamide formation in these biscuits (Fig. 2).

The category of the cereal-mixture, in which the presence of corn, rice, wheat and spelt was predominant in the formulation, exhibited medium-low acrylamide content $\left(293 \mu \mathrm{g} \mathrm{kg}^{-1}\right.$, range: $75-595 \mu \mathrm{g} \mathrm{kg}^{-1}$ ). In the case of soy-based biscuits, the concentration of the contaminant was 3-fold higher than that detected in wheat-based biscuits (662 vs. $226 \mu \mathrm{g} \mathrm{kg}^{-1}$ ), although no conclusion can be drawn since only one sample was evaluated in the present study. In the same line, Žilić ${ }^{25}$ described an outright increase in acrylamide level when soy was added to the formulation of conventional wholemeal cookies (from 170 to $\left.496 \mu \mathrm{g} \mathrm{kg}^{-1}\right)$. 


\subsection{Factors affecting acrylamide occurrence in biscuits}

Besides the type of cereal, it is important to consider other ingredients that can also provide acrylamide precursors and then promote its formation in biscuits. ${ }^{9}$ Therefore, samples were grouped according to additional factors: type of grain (refined/wholegrain), protein content (below or above $7.5 \%$ ), fibre content (below or above 5\%), sugar content (below or above $20 \%$ ), presence of butter, egg, sodium carbonate or ammonium carbonate in the recipe, gluten free (yes/no) and target consumption (normal/dietetic) (Table 2). Recently, our research group has performed a prospective study in breakfast cereals establishing that acrylamide content was significantly higher in cereals made from wholegrain $\left(152 \mu \mathrm{g} \mathrm{kg} \mathrm{kg}^{-1}\right)$ as compared with those made from refined grains $\left(70 \mu \mathrm{g} \mathrm{kg} \mathrm{kg}^{-1}\right)$ $(p<0.05)$. However, classification according to the protein, fibre and sugar content as well as the presence of honey or the target consumer (children/general population) did not influence the levels of the contaminant in those cereal-based products. $^{26}$ The current investigation of biscuits indicates that the use of wholegrain increases the average acrylamide content by nearly $50 \%$ compared with refined grains, although no significant differences were observed $(p>0.05)$. Similarly, biscuits with higher levels of protein and fibre presented higher content of acrylamide, but without significant differences. This finding agrees with the acrylamide toolbox, which affirms that using less whole meal and/or less bran and germ and more endosperm may result in lower acrylamide levels as free asparagine is more concentrated in the germ/bran. ${ }^{9}$

Acrylamide levels were significantly higher when sugar content was lower than $20 \%(p=0.015)$. This result is contradictory to the mechanism of formation of acrylamide in bakery products, since reducing sugars will provide the carbonyl group necessary to the reaction with asparagine in the dough during baking. However, it has to be taken into account that the sugar level has been reported from the label of the finished product and does not reflect the initial reducing sugar content in the recipe. In this sense, it could be expected that sugar levels decrease if they are consumed to generate acrylamide during baking.

Although the presence of butter in the formulation seems to decrease the acrylamide content in biscuits, the great variability among recipes without butter meant the differences were not significant. Moreover, only six samples with butter were analysed, which is insufficient to draw a clear conclusion. Despite this, our data are in agreement with the trend observed by Tawfik and El-Ziney, ${ }^{27}$ who detected low acrylamide content in butter cookies compared with traditional ones (151 vs. $810 \mu \mathrm{g} \mathrm{kg} \mathrm{kg}^{-1}$ ). Regarding the presence of egg in the formulation, it is estimated that $12 \%$ of egg weight corresponds to proteins. Although specific information about its asparagine content has not been found in the literature, this food has traditionally been considered a source of amino acids. ${ }^{28}$ However, our results depicted that the presence of egg in biscuits did not promote acrylamide formation, but the contrary (150 vs. $386 \mu \mathrm{g} \mathrm{kg}^{-1}$, respectively).
Due to the higher prevalence of celiac disease around the world, ${ }^{29}$ gluten-free product commercialisation has grown at an annual rate of $28 \% .{ }^{30}$ These products are formulated with glutenfree cereals and other ingredients, offering alternative food intended for people with this disease. In this study, biscuits with and without gluten exhibited a similar acrylamide content and also those classified as dietetic biscuits, where the low fat and/or sugar content did not significantly affect acrylamide levels.

According to the product labelling, acrylamide concentration depended neither on the presence of sodium carbonate nor ammonium carbonate in the final product. Both ingredients are chemical leavening agents used in the dough of bakery products to promote an increase in volume and modify the shape and texture. ${ }^{31}$ Ammonium bicarbonate enhances acrylamide formation in bakery products, which has been demonstrated in gingerbread ${ }^{32}$ and shortbread. ${ }^{33}$ Amrein et $a .^{32}$ affirmed that this increase is probably indirectly promoted by the ability of ammonium bicarbonate to provide acrylamide precursors such as carbonyl compounds (glyoxal and methylglyoxal originating from the reaction of ammonia with reducing sugars). ${ }^{32}$ Sodium bicarbonate is another alternative and its use seems to decrease acrylamide levels by increasing the $\mathrm{pH}$ of the system. The partial or total replacement of ammonium bicarbonate by sodium bicarbonate has been studied by several authors. Decreases in acrylamide levels by one-third in gingerbread ${ }^{32}$ and by over $70 \%$ in biscuits ${ }^{34}$ were described when ammonium bicarbonate was totally replaced by sodium bicarbonate. However, this effect was not observed if the replacement was not complete. ${ }^{34}$ Acrylamide concentrations were also lower when ammonium bicarbonate was included in the formulation of crackers. ${ }^{35}$ These studies affirmed that, besides decreasing the acrylamide formation, sodium bicarbonate promotes acrylamide elimination, which is another positive aspect of using this baking agent. Although acrylamide content in the current samples tends to be higher in the presence of both chemical agents, the great variability among the samples makes these differences not significant (Table 2). These data are not in agreement with results previously reported by Rufián-Henares et al., ${ }^{10}$ where biscuits with ammonium hydrogencarbonate showed significantly higher concentrations of acrylamide $\left(1549 \mu \mathrm{g} \mathrm{kg}^{-1}\right)$ as compared with biscuits without $\mathrm{NH}_{4} \mathrm{HCO}_{3}\left(230 \mu \mathrm{g} \mathrm{kg}{ }^{-1}\right)$. It is noteworthy to mention that formula readjustment, the use of processing aids, the use of asparaginase, and mild processing conditions applied currently during the industrial production of biscuits greatly influence the results of the present study as compared with those obtained in 2007.

\subsection{Evaluation of acrylamide exposure from Spanish commercialised biscuits}

Due to the association between acrylamide intake and the risk of developing some types of cancer, ${ }^{5}$ exposure to this contaminant has turned into a public health concern and a priority for the food safety authorities of many developed countries.

Since biscuits are an important acrylamide source in the common diet of all age populations, the calculation of the 
Table 3 Daily exposure to acrylamide considering the whole dataset for biscuits and those grouped based on the predominant cereal

\begin{tabular}{ll}
\hline Predominant cereal & Acrylamide $\left(\mu \mathrm{g}_{\text {day }}{ }^{-1}\right)$ \\
\hline Wheat $(n=47)$ & $3.23 \pm 2.78$ \\
Corn $(n=4)$ & $1.91 \pm 2.44$ \\
Oat $(n=7)$ & $8.38 \pm 6.83$ \\
Rice $(n=4)$ & $3.59 \pm 5.52$ \\
Spelt $(n=6)$ & $9.07 \pm 4.79$ \\
Rye $(n=1)$ & 30.60 \\
Teff $(n=2)$ & $20.01 \pm 3.17$ \\
Buckwheat $(n=2)$ & $2.44 \pm 1.42$ \\
Soy $(n=1)$ & 9.45 \\
Mixture $(n=6)$ & $4.18 \pm 3.09$ \\
Mean value & $4.96 \pm 5.55$ \\
\end{tabular}

acrylamide exposure from this food category for the Spanish population was considered necessary. Data were obtained using the information of total per capita consumption of this foodstuff established by the Spanish Ministry of Agriculture, Food and Environment (5.24 $\mathrm{kg}$ per person per year) ${ }^{12}$ and the acrylamide content in the sampled biscuits (Table 3). When different predominant grains were considered, exposure was calculated assuming that all the biscuits consumed in a year came from the same group.

As expected due to the acrylamide levels found in the different groups of biscuits, rye-based biscuits present the highest exposure level, followed by teff, spelt and oat-based ones, ranging from 30.60 to $8.38 \mu \mathrm{g} \mathrm{day}^{-1}$. Consumption of biscuits made of cereal mixture as well as those mainly formulated with rice and wheat leads to a median acrylamide exposure (4.18-3.23 $\left.\mu \mathrm{g} \mathrm{day}^{-1}\right)$, while a low exposure scenario takes place if buckwheat or corn-based biscuits are selected (2.44-1.91 $\mu \mathrm{g}$ day $\left.^{-1}\right)$.

Taking into account the mean acrylamide content for the overall sampling, the exposure to acrylamide is estimated to be $4.96 \mu \mathrm{g}$ per day, or $0.071 \mu \mathrm{g}$ per $\mathrm{kg}$ body weight per day considering a standard adult weight of $70 \mathrm{~kg}$. This figure cannot be compared with the estimation performed by our previous study in 2007 , since at that moment the biscuit consumption of the Spanish population was not separated from that of bread derivatives. ${ }^{10}$

In 2009, the Food Safety Authority of Ireland estimated the mean dietary exposure to acrylamide as $0.6 \mu \mathrm{g}$ per $\mathrm{kg}$ body weight per day for the Irish adult population, assigning a $10 \%$ contribution to the biscuit category. ${ }^{36}$ It supposed a daily input of $4.2 \mu \mathrm{g}$ of acrylamide from this foodstuff for a $70 \mathrm{~kg}$ adult, a value very close to that established in the present study. On the other hand, the exposure data calculated from biscuits are similar to the $95^{\text {th }}$ percentile indicated by Svensson $e t$ al..$^{13}$ and to the $90^{\text {th }}$ percentile described in a recent study by Normandin et al. ${ }^{37}$

\subsection{Evolution of acrylamide levels in biscuits marketed in Spain from 2007 to 2019}

During the last decade, international organizations have promoted the introduction of acrylamide mitigation measures among the food industry with the aim of reducing the formation of this contaminant during processing of food and, consequently, the exposure through the diet. Several strategies have been recommended in the Toolbox of acrylamide and, specifically for biscuit products, they are intended to control recipe and product design, shape and piece size, processing and final preparation. ${ }^{8,9}$ In addition, since the publication of the Regulation, these recommendations are being specially followed in order to ensure acrylamide levels lower than the benchmark values for each food matrix. In this regard and with the objective of evaluating the effectiveness of the mitigation measures after 12 years, the results of the present study were compared with those of our previous study on biscuits marketed in Spain. ${ }^{10}$ It is noteworthy to mention that a single quadrupole mass spectrometer was used for the analysis in 2007 instead of a triple quadrupole mass spectrometer used in the current study.

Comparison of the overall sampling carried out in 2007 and the reassessed value in 2019 is presented in Fig. 3A. Although mean values in 2019 tend to decrease as compared with results in 2007 (348 and $424 \mu \mathrm{g} \mathrm{kg}^{-1}$, respectively), differences were not significant. However, it has to be highlighted that in 2019, sampling includes biscuits with new types of cereals, whose composition, in many cases, promotes the formation of acrylamide as compared with the traditional composition based on wheat. In 2007, from the 62 samples analysed, 59 were wheat-based biscuits and only 2 products were formulated with oat and 1 with rice. Therefore, to be consistent with the categories studied in 2007 , only wheat-based biscuits have been included for the comparison (59 biscuits from 2007 study vs. 47 biscuits from 2019 study) (Fig. 3B). A significant decrease ( $c a .45 \%)$ in the mean acrylamide content was observed; therefore, the acrylamide mitigation strategies applied by the biscuit manufactures have been effective. These findings could be justified by the readjustment of recipes (i.e. reducing or replacing ammonium bicarbonate) and processes (i.e. optimisation of the thermal input), as well as by the use of asparaginase enzyme which catalyses the hydrolysis of asparagine in aspartic acid and ammonia and whose application as a mitigation strategy is widening in this sector. ${ }^{9}$ Capuano et al. ${ }^{38}$ assessed the acrylamide content in bread crisp toasted for different times and concluded that asparaginase added to the dough of bread led to a reduction of up to $80 \%$.

The EFSA's Scientific Report described a reduction in the mean levels of acrylamide in the category of "biscuits, crackers, crisp bread and similar products" from $309 \mu \mathrm{kg}^{-1}$ to $180 \mu \mathrm{g} \mathrm{kg}^{-1}$ during 2007 to 2010 . However, the levels increased in $2010\left(289 \mu \mathrm{g} \mathrm{kg}^{-1}\right)$. A similar trend was observed for maximum levels, which decreased from $4200 \mu \mathrm{g} \mathrm{kg}^{-1}$ in 2007 to $1940 \mu \mathrm{g} \mathrm{kg}^{-1}$ in 2009 , but increased to $2650 \mu \mathrm{g} \mathrm{kg}^{-1}$ in 2009 and even to $5849 \mu \mathrm{g} \mathrm{kg}^{-1}$ in 2010 , exceeding the concentrations described four years ago. ${ }^{39}$ In those samples the type of cereal was not specified. However, due to the changes in the current recipe of biscuits, it is quite likely that many of them incorporated cereals other than wheat in the formulation, being responsible for the increase in acrylamide levels. Our 

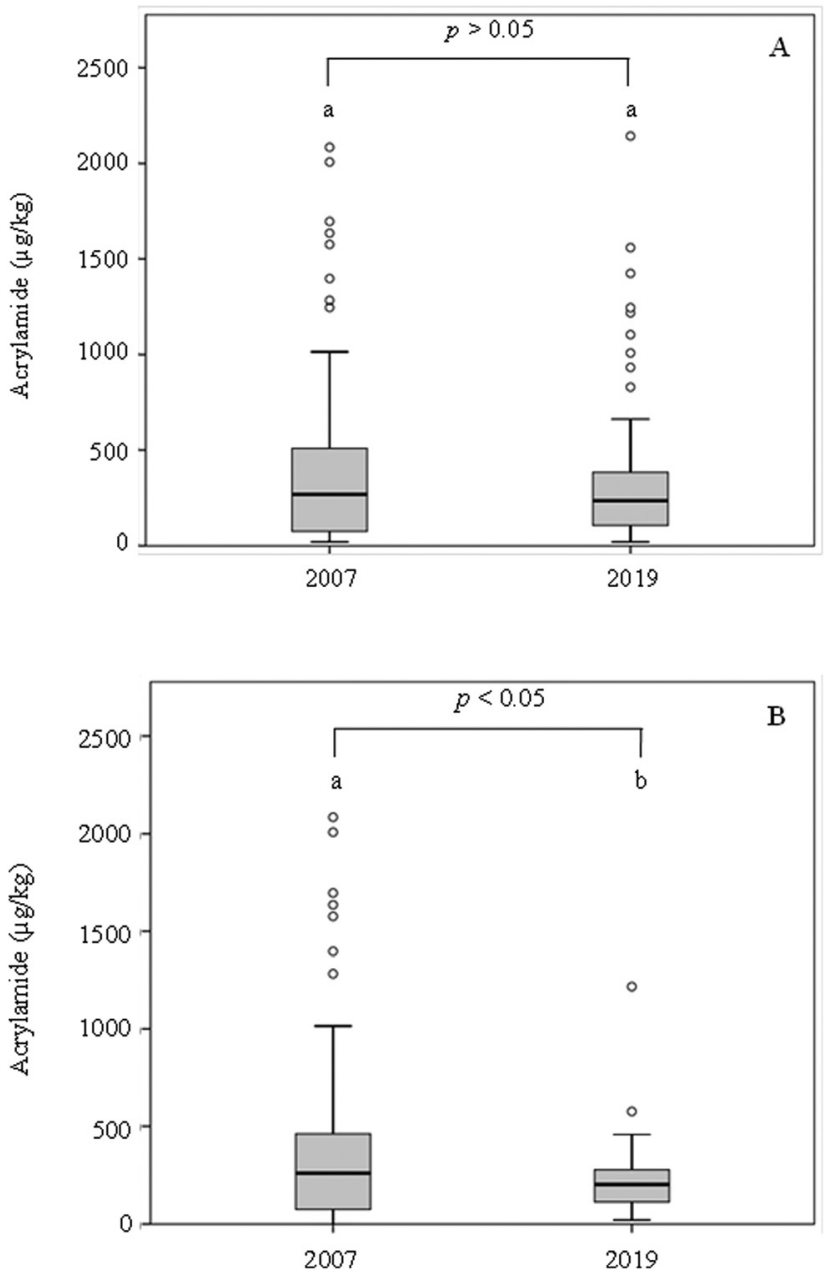

Fig. 3 Comparison between acrylamide content in biscuits in 2007 vs. 2019. (A) Box-and-whisker plot of acrylamide content in the whole group of biscuits. (B) Comparison of the acrylamide content in wheatbased biscuits. Different letters indicate significant differences between years $(p<0.05)$.

investigation pointed out that acrylamide in biscuits is linked to the replacement of wheat flour with other cereals or pseudocereals. Therefore, new formulations should be evaluated not only from a nutritional point of view, but also considering the risk of the increase of process contaminants using a risk/ benefit approach. Since the type of cereal clearly affects the acrylamide content, next reviews of the regulation should consider establishing categories in biscuits according to the main cereal in the recipe, as has already been included in breakfast cereals. $^{8}$

\section{Conclusions}

Acrylamide levels in biscuits marketed in Spain show a great variability, ranging from lower than $20 \mu \mathrm{g} \mathrm{kg}^{-1}$ to $2144 \mu \mathrm{g}$ $\mathrm{kg}^{-1}$. Compared to the benchmark level established by the European Regulation for biscuits and wafers $\left(350 \mu \mathrm{g} \mathrm{\textrm {kg } ^ { - 1 }}\right.$ ), $30 \%$ of the samples exceed the reference level. In order to monitor the evolution of acrylamide in this food category over the years and to check the effectiveness of the mitigation strategies applied by the biscuit industry, the results were compared with data reported by our research group in 2007. Based on 2007 vs. 2019 comparison, acrylamide occurrence in the Spanish biscuit market has experienced an important decline $(45 \%)$ in wheat-based formulations, demonstrating the effectiveness of the mitigation strategies applied by the sector. However, a non-significant slight decrease (18\%) was observed for the whole dataset, considering also the novel formulations with innovative ingredients. Since multi-cereal biscuits were scarcely present in the sampling of 2007 and have considerably increased in 2019, the new formulations based on cereals other than wheat are identified as the main contributors to the increase in acrylamide exposure from biscuits. This evidence needs further attention from the food safety administration bodies and the biscuit industry sector. The next update of the acrylamide Regulation should consider establishing categories in biscuits according to the main cereal present in the biscuit, as has already been established in breakfast cereals.

\section{Conflicts of interest}

The authors declare that they have no conflict of interest.

\section{Acknowledgements}

This work was partially supported by the Comunidad of Madrid and European funding from FSE and FEDER programs (project S2018/BAA-4393, AVANSECAL-II-CM) and by the project CSIC-201770I025 (Spanish National Research Council). The authors thank Ms. I. Alvarez, B. Díaz and C. Escudero for their technical assistance.

\section{References}

1 L. Ait-Ameur, G. Trystram and I. Birlouez-Aragon, Accumulation of 5-hydroxymethyl-2-furfural in cookies during the baking process: validation of an extraction method, Food Chem., 2006, 98, 790-796.

2 CAOBISCO (Chocolate, Biscuit \& Confectionery of Europe). Working towards people's need. In Annual report 2016, 2017, Caobisco, Belgium. http://caobisco.eu/caobisco-chocolate-biscuits-confectionery-europe-page-41-Annual-Report. html\#.XScD9OgzZPZ (Access July 2019).

3 S. S. Sablani, M. Marcotte, O. D. Baik and F. Castaigne, Modeling of simultaneous heat and water transport in the baking process, LWT - Food Sci. Technol., 1998, 31, 201209.

4 R. H. Stadler, I. Blank, N. Varga, F. Robert, J. Hau, P. A. Guy, M. C. Robert and S. Riediker, Acrylamide from Maillard reaction products, Nature, 2002, 419, 449.

5 EFSA (European Food Safety Agency), Scientific opinion on acrylamide in food, EFSA J., 2015, 13, 4104 http://www.efsa. 
europa.eu/sites/default/files/scientific_output/files/main documents/4104.pdf (accessed June 2019).

6 Commission Recommendation, Investigations into the levels of acrylamide in food, Official Journal of the European Union, 2011, http://ec.europa.eu/food/food/chemi-calsafety/ contaminants/recommendation_10012011_acrylamide_food_ en.pdf (accessed June 2019).

7 Commission Recommendation, Investigations into the levels of acrylamide in food, Off. J. Eur.Union, 2013, L301/15.

8 European Commission, Commission Regulation (EU) 2017/ 2158 of 20 November 2017 establishing mitigation measures and benchmark levels for the reduction of the presence of acrylamide in food, Off. J. Eur.Union, 2017, L304, 24-44.

9 FoodDrinkEurope (FDE), 2019. Acrylamide Toolbox 2019. https://www.fooddrinkeurope.eu/uploads/publications _ documents/FoodDrinkEurope_Acrylamide_Toolbox_2019. pdf (accessed June 2019).

10 J. A. Rufián-Henares, G. Arribas-Lorenzo and F. J. Morales, Acrylamide content of selected Spanish foods: Survey of biscuits and bread derivatives, Food Addit. Contam., 2007, 24, 343-350.

11 M. Mesías and F. J. Morales, Acrylamide in commercial potato crisps from Spanish market: Trends from 2004 to 2014 and assessment of the dietary exposure, Food Chem. Toxicol., 2015, 81, 104-110.

12 MAPA (Ministerio de Agricultura, Pesca y Alimentación), 2019. Informe del consumo alimentario en España 2018. https://www.mapa.gob.es/es/alimentacion/temas/consumo-ycomercializacion-y-distribucion-alimentaria/20190624_informedeconsumo2018pdf_tcm30-510816.pdf (accessed June 2019).

13 K. Svensson, L. Abramsson, W. Becker, A. Glynn, K. E. Hellenäs, Y. Lind and J. Rosén, Dietary intake of acrylamide in Sweden, Food Chem. Toxicol., 2003, 41, 15811586.

14 R. Capei, L. Pettini, A. Lo Nostr and G. Pesavento, Occurrence of Acrylamide in breakfast cereals and biscuits available in Italy, J. Prev. Med. Hyg., 2015, 56, E190-E195.

15 C. Matthys, M. Bilau, Y. Govaert, E. Moons, S. De Henauw and J. L. Willems, Risk assessment of dietary acrylamide intake in Flemish adolescents, Food Chem. Toxicol., 2005, 43, 271-278.

$16 \mathrm{H}$. A. Alyousef, H. Wang, N. Q. M. Al-Hajj and M. Y. F. Koko, Determination of acrylamide levels in selected commercial and traditional foods in Syria, Trop. J. Pharm. Res., 2016, 15, 1275-1281.

17 M. F. Cengiz and C. P. B. Gündüz, Acrylamide exposure among Turkish toddlers from selected cereal-based, Food Chem. Toxicol., 2013, 60, 514-519.

18 W. C. Cheng, D. C. Sun, S. S. Chou and A. I. Yeh, Acrylamide content distribution and possible alternative ingredients for snack foods, J. Food Prot., 2012, 75, 21582162.

19 R. H. Stadler and A. Studer, Acrylamide Formation Mechanisms, in Acrylamide in food. Analysis, content and potential health effects, ed. V. Gökmen, Academic Press, London, UK, 2015, ch. 1.

20 K. Granby, N. J. Nielsen, R. V. Hedegaard, T. Christensen, M. Kann and L. H. Skibsted, Acrylamide-asparagine relationship in baked/toasted wheat and rye breads, Food Addit. Contam., 2008, 25, 921-929.

21 M. Przygodzka, M. K. Piskula, K. Kukurová, Z. Ciesarová, A. Bednarikova and H. Zielinski, Factor influencing acrylamide formation in rye, wheat and spelt breads, J. Cereal Sci., 2015, 65, 96-102.

22 A. Claus, P. Schreiter, A. Weber, S. Graeff, W. Herrmann, W. Claupein, A. Schieber and R. Carle, Influence of Agronomic Factors and Extraction Rate on the Acrylamide Contents in Yeast-Leavened Breads, J. Agric. Food Chem., 2006, 54, 8968-8976.

23 S. Žilić, D. Dodig, Z. Basić, J. Vančetović, P. Titan, N. Đurić and N. Tolimir, Free asparagine and sugars profile of cereal species: the potential of cereals for acrylamide formation in foods, Food Addit. Contam., 2017, 34, 705-713.

24 A. R. Adebowale, M. Emmambux, M. Beukes and J. Taylor, Fractionation and characterization of teff proteins, J. Cereal Sci., 2011, 54, 380-386.

25 S. Žilić, Acrylamide in Soybean Products, Roasted Nuts, and Dried Fruits, in Acrylamide in Food. Analysis, content and potential health effects, ed. V. Gökmen, Academic Press, London, UK, 2015, ch. 10.

26 M. Mesías, L. Sáez-Escudero, F. J. Morales and C. DelgadoAndrade, Reassessment of acrylamide content in breakfast cereals. Evolution of the Spanish market from 2006 to 2018, Food Control, 2019, 105, 94-101.

27 M. S. Tawfik and M. G. El-Ziney, Acrylamide Levels in Selected Foods in Saudi Arabia with Reference to HealthRisk Assessment of Dietary Acrylamide Intake, Am. J. Food Technol., 2008, 3, 347-353.

28 N. Wang, A. Seko, Y. Takeda and Y. Ito, Preparation of asparagine-linked monoglucosylated high-mannosetype oligosaccharide from egg yolk, Carbohydr. Res., 2015, 441, 37-41.

29 D. Schuppan, Y. Junker and D. Barisani, Celiac Disease: From Pathogenesis to Novel Therapies, Gastroenterology, 2009, 137, 1912-1933.

$30 \mathrm{~K}$. Glover, 2009. Companies expand gluten free offerings. http:/industry.bnet.com/food/1000549/companies-expandgluten-freofferings/(accessed June 2019).

$31 \mathrm{H}$. M. Lai and T. C. Lin, Bakery products: science and technology, in Bakery products. Science and technology, ed. H. Y. Hui, Blackwell Publishing Professional, Iowa, USA, 2006, ch. 1.

32 T. M. Amrein, B. Schönbächler, F. Escher and R. Amadó, Acrylamide in gingerbread: Critical factors for formation and possible ways for reduction, J. Agric. Food Chem., 2004, 52, 4282-4288.

33 O. Marconi, E. Bravi, G. Perretti, R. Martini, L. Montanari and P. Fantozzi, Acrylamide risk in food products: the shortbread case study, Anal. Methods, 2010, 2, 1686-1691. 
34 M. Graf, T. M. Amrein, S. Graf, R. Szalay, F. Escher and R. Amadò, Reducing the acrylamide content of a semi-finished biscuit on industrial scale, LWT - Food Sci. Technol., 2006, 39, 724-728.

35 R. A. Levine and R. E. Smith, Sources of variability of acrylamide levels in a cracker model, J. Agric. Food Chem., 2005, 53, 4410-4416.

36 Food Safety Authority of Ireland (FSAI), Acrylamide in Food, Toxicol. Factsheet Series, 2009, 1, 1-7.

37 L. Normandin, M. Bouchard, P. Ayotte, C. Blanchet, A. Becalski, Y. Bonvalot, D. Phaneuf, C. Lapointe, M. Gagné and M. Courteau, Dietary exposure to acrylamide in adolescents from a Canadian urban center, Food Chem. Toxicol., 2013, 57, 75-83.

38 E. Capuano, A. Ferrigno, I. Acampa, L. Ait-Ameur and V. Fogliano, Characterization of the Maillard reaction in bread crisps, Eur. Food Res. Technol., 2008, 228, 311319.

39 EFSA (European Food Safety Authority), 2012. Update on acrylamide levels in food from monitoring years 2007 to 2010. https://efsa.onlinelibrary.wiley.com/doi/epdf/10.2903/ j.efsa.2012.2938 (accessed June 2019). 